\title{
The association of rubeosis iridis with endothelialisation of the anterior chamber: report of a clinical case with histopathological review of 16 additional cases
}

\author{
SAMUEL GARTNER, SIMEON TAFFET, AND ALAN H. FRIEDMAN \\ From the Department of Ophthalmology, Albert Einstein College of Medicine, \\ Montefiore Hospital and Medical Center
}

\begin{abstract}
SUMMARY A patient is reported in whom the clinical observation of extension of the corneal endothelium and Descemet's membrane in association with rubeosis iridis was confirmed by histopathological examination. In a study of eyes which had been removed and demonstrated rubeosis iridis and secondary glaucoma 16 additional eyes revealed extension of the corneal endothelium and Descemet's membrane on to the anterior iris surface. In all instances the transition occurred at the pseudoangle formed by the attachment of peripheral anterior synechiae. The suggestion is made that the fibrovascular membrane of rubeosis iridis is the stimulus which excites the extension of the endothelium on to the iris surface. The association between rubeosis iridis and extension of the corneal endothelium and Descemet's membrane on to the iris has not been previously appreciated.
\end{abstract}

The extension of corneal endothelium and Descemet's membrane on to the anterior iris surface has been reported: (1) in the presence of peripheral anterior synechiae; (2) in association with the irisnaevus syndrome; (3) on the trabecular meshwork following traumatic angle recession; and (4) in essential iris atrophy. When examining a patient's blind eye prior to enucleation we observed a glasslike membrane on the anterior surface of the iris in association with ectropion uveae, peripheral anterior synechiae, and rubeosis iridis. Histopathological confirmation of the clinical findings led us to undertake a retrospective study of enucleated eyes displaying rubeosis iridis and peripheral anterior synechiae which also showed extension of corneal endothelium and Descemet's membrane on to the anterior iris surface.

This work was supported in part by National Eye Institute Grant No. R01-EY00613-04 and Seeing Eye Inc, Morristown, New Jersey 07960.

Address for reprints: Dr Alan H. Friedman, Montefiore Hospital and Medical Center, 111 East 210th Street, Bronx, New York 10467, USA.

\section{Case report}

A 50-year-old man was examined in September 1975 because of an irritated, blind right eye. He had been struck by a snowball at age 11 and had subsequently undergone a slow, progressive loss of vision. The patient had been in excellent health all his life. On examination in 1975 his corrected visual acuity was no light perception right eye and 20/20 left eye. Intraocular pressure was $16 \mathrm{mmHg} O D$ and $18 \mathrm{mmHg}$ OS, by applanation. The left eye was entirely normal, while examination of the right eye revealed a moderately hyperaemic conjunctiva, clear cornea, and an anterior chamber much deeper than on the right associated with a posteriorly dislocated, cataractous and partially calcified lens. The anterior chamber angle was closed for $360^{\circ}$ by broad peripheral anterior synechiae. The iris displayed $360^{\circ}$ of extensive ectropion uveae with the iris pigment epithelium reflected nearly $50 \%$ on to the anterior iris surface (Fig. 1). Where the ectropion ceased, a prominent rubeosis iridis was apparent. Overlying the rubeosis iridis a glass-like, gossamer membrane was present on the anterior iris surface extending 

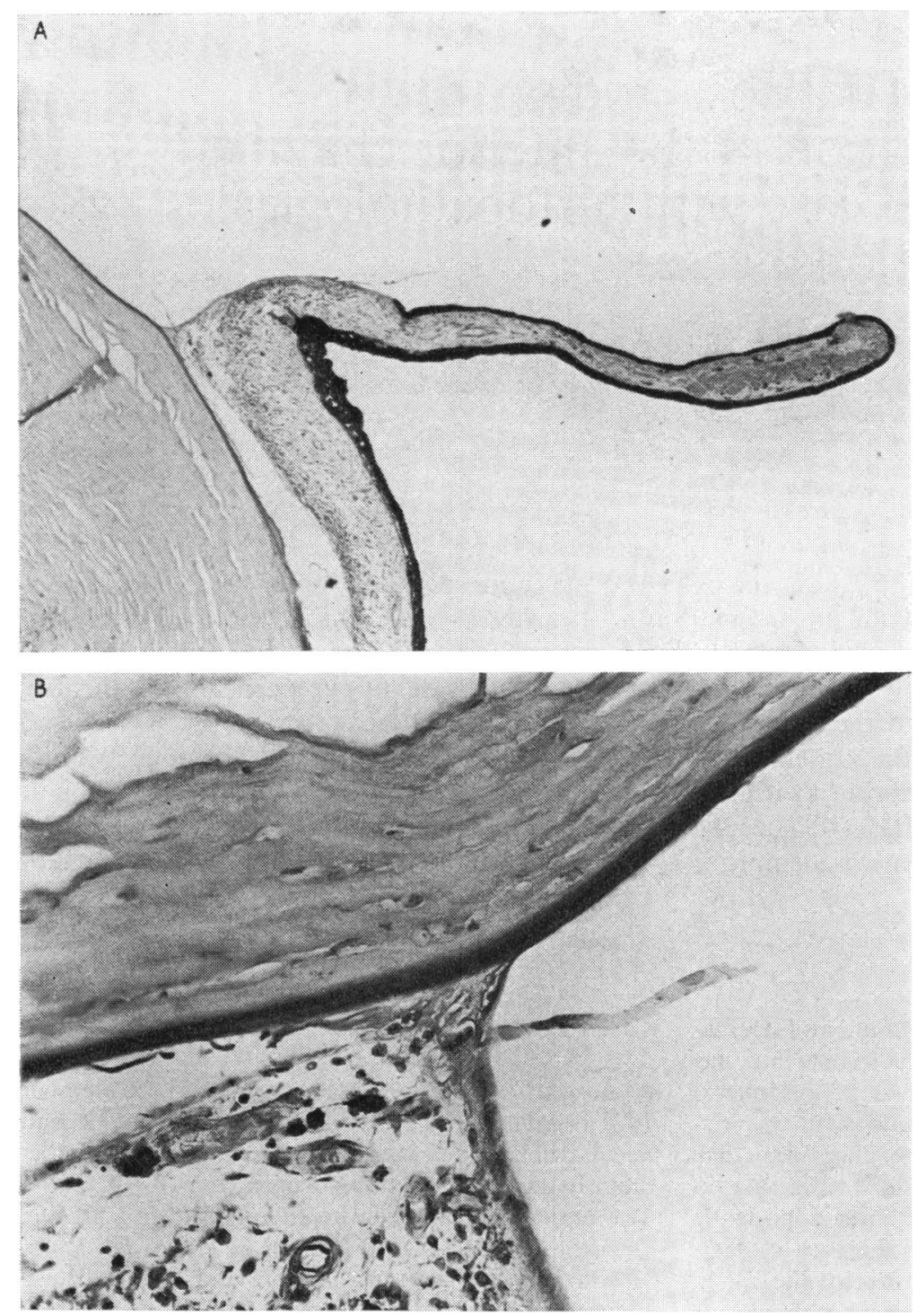

Fig. 1 A. Photomicrograph revealing extensive ectropion uveae with rubeosis iridis. $H$ and $E . \quad \times 50$. B. Higher power view of angle showing extension of endothelium and Descemet's membrane on to iris. PAS. $\times 315$ from the pseudoangle formed at the termination of the peripheral anterior synechiae to the border of the ectropion uvea. The retina was totally detached as delineated by contact B-scan ultrasonography. The eye was enucleated.

\section{Histopathological study}

GROSS EXAMINATION

The specimen consisted of an intact right eye measuring $26 \times 26 \times 24 \mathrm{~mm}$. The cornea measured $12.5 \times 11.5 \mathrm{~mm}$ and was clear. The pupil measured $4 \mathrm{~mm}$ in diameter and the iris showed a marked ectropion uveae. The eye was opened horizontally and the retina displayed a total detachment with a large amount of crystalline material in the subretinal space. A dislocated, cataractous lens was present inferiorly.

\section{MICROSCOPIC EXAMINATION}

The subconjunctival tissue showed a moderate round cell infiltration. The cornea was unremarkable, and the anterior chamber angle on both sides showed evidence of a previous angle recession with secondary peripheral anterior synechiae. At the site of the recession there was some fibrosis. The iris 
was markedly thinned and showed a very prominent ectropion uveae. A fibrovascular membrane was present on the iris surface extending from the peripheral anterior synechiae to the ectropion uveae. At the pseudoangle there was extension of Descemet's membrane and endothelium on to the anterior surface of the iris (Fig. 1). The dislocated lens was calcified and the totally detached retina was atrophic.

\section{Impression}

(1) Anterior chamber angle recession.

(2) Peripheral anterior synechiae.

(3) Rubeosis iridis.

(4) Ectropion uveae.

(5) Extension of endothelium and Descemet's membrane on to the anterior surface of the iris.

(6) Total retinal detachment.

(7) Cataract with calcification.

\section{Case material}

The findings in our case prompted us to undertake a retrospective study of enucleated eyes. In our histopathological collection of eyes with rubeosis iridis we found 16 globes which also had an extension of the corneal endothelium and Descemet's membrane on to the iris. The results in these cases are summarised in Table 1 . Of the 16 eyes displaying an extension of Descemet's membrane on to the iris 14 eyes were surgical enucleations and 2 were postmortem specimens. Seven of the eyes had severe trauma, 3 eyes had previous cataract extractions, 2 followed central artery occlusion, and 1 patient with diabetes mellitus had had radiation therapy (Table 2).

The corneal endothelium and Descemet's membrane grew from the cornea on to the anterior iris surface at the pseudoangle formed by the attachment of the iris to the cornea and then extended for a variable distance on to the anterior surface of the iris. This membrane was firmly attached to the iris by the fibrovascular membrane typical of rubeosis iridis. Many of the globes had ectropion uveae and pupillary membranes as well. The layer of newformed Descemet's membrane was thick and prominent and extended over most of the iris in 6 patients (Fig. 2). In 10 cases the membranes were

Table 1 Summary of cases

\begin{tabular}{|c|c|c|c|c|c|c|}
\hline Case & Age & $\operatorname{Sex}$ & Antecedent history & Clinical eye diagnosis & $\begin{array}{l}\text { Peripheral } \\
\text { anterior synechiae }\end{array}$ & $\begin{array}{l}\text { Rubeosis } \\
\text { iridis }\end{array}$ \\
\hline 1 & 68 & $\mathbf{F}$ & $\begin{array}{l}\text { Extra-capsular } \\
\text { Cataract extraction } \\
\text { Cardiac failure }\end{array}$ & $\begin{array}{l}\text { Glaucoma, } \\
\text { Bullous keratopathy }\end{array}$ & Present & Present \\
\hline 2 & 73 & $\mathbf{M}$ & $\begin{array}{l}\text { Intra-capsular } \\
\text { Cataract extraction } \\
\text { Diabetes mellitus }\end{array}$ & Glaucoma & Present & Present \\
\hline 3 & 22 & $\mathbf{F}$ & $\begin{array}{l}\text { Intraocular foreign body } 12 \text { years } \\
\text { ago. Retinal detachment operation }\end{array}$ & Blind painful eye & Present & Present \\
\hline 4 & 21 & $\mathbf{M}$ & Blunt injury 13 years ago & Glaucoma, Rubeosis iridis & Present & Present \\
\hline 5 & 64 & $\mathbf{M}$ & Blunt injury 46 years ago & Absolute glaucoma & Present & Present \\
\hline 6 & 52 & $\mathbf{F}$ & Blunt injury ? date & $\begin{array}{l}\text { Glaucoma, Rubeosis iridis, } \\
\text { cataract }\end{array}$ & Present & Present \\
\hline 7 & 58 & $\mathbf{M}$ & Blunt injury? date & Painless blind eye & Present & Present \\
\hline 8 & 48 & $\mathbf{F}$ & Blunt trauma $2 \frac{1}{2}$ years ago & Absolute glaucoma & Present & Present \\
\hline 9 & 14 & $\mathbf{F}$ & Trauma-age 3 & Glaucoma & Present & Present \\
\hline 10 & $?$ & $?$ & Trauma & Sympathetic ophthalmia & Present & Present \\
\hline 11 & $?$ & $\mathbf{F}$ & Central retinal artery occlusion & Absolute glaucoma & Present & Present \\
\hline 12 & 89 & $\mathbf{F}$ & Central retinal artery occlusion & Absolute glaucoma & Present & Present \\
\hline 13 & 54 & $\mathbf{F}$ & $\begin{array}{l}\text { Diabetes. Radiation therapy for } \\
\text { Rubeosis iridis }\end{array}$ & Absolute glaucoma & Present & Present \\
\hline 14 & 42 & $\mathbf{M}$ & Bilateral Peters's Anomaly & Peters's anomaly & Present & Present \\
\hline 15 & 57 & $\mathbf{F}$ & $?$ & Phthisis bulbi & Present & Present \\
\hline 16 & $?$ & $\mathbf{F}$ & $?$ & $?$ & Present & Present \\
\hline
\end{tabular}



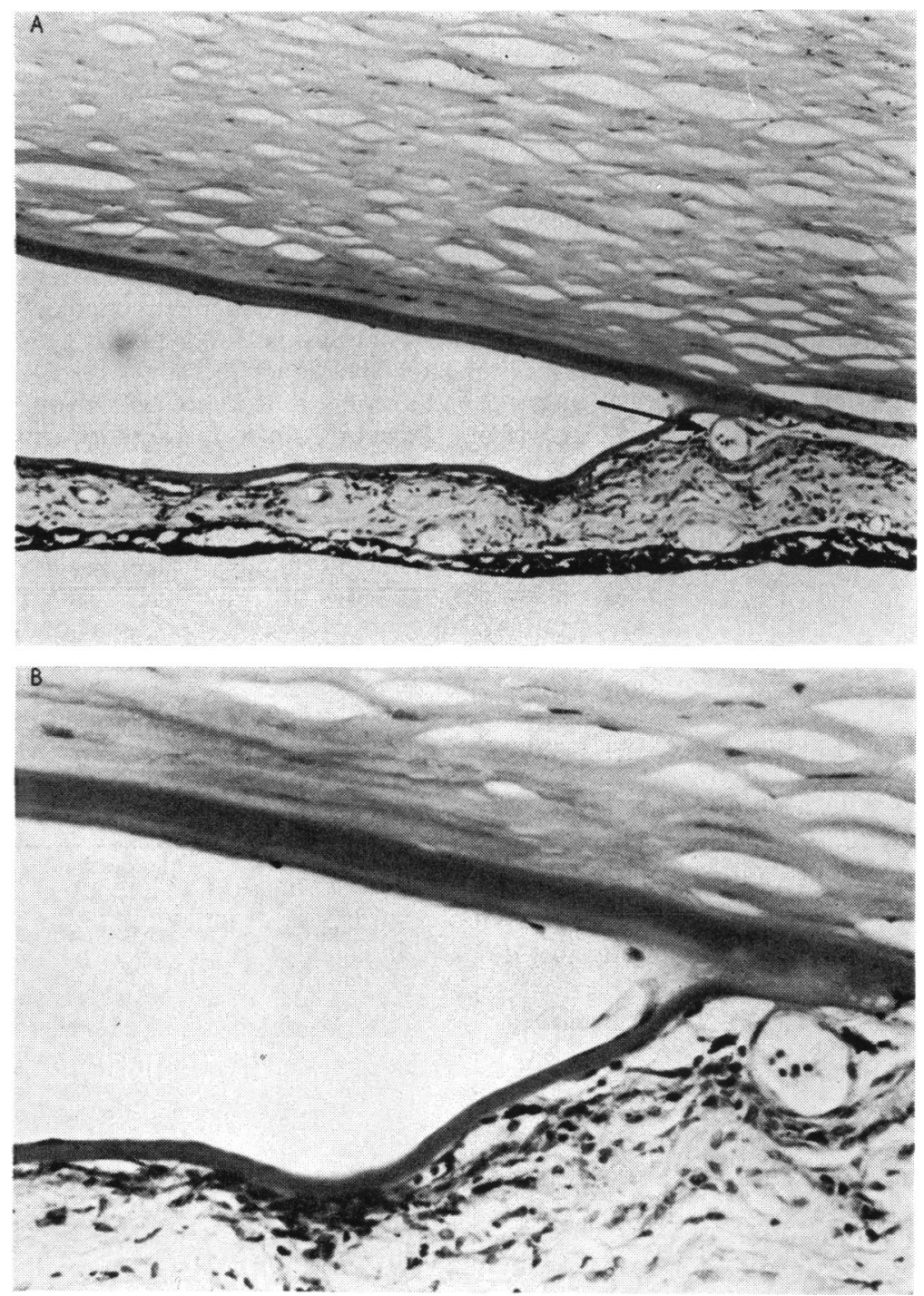

Fig 2 A. Photomicrograph of case 7 showing prominent rubeosis iridis in presence of extension of endothelium and Descemet's membrane on to anterior iris surface. PAS. $\times 135$. B. Higher power view showing prominent vessels between newformed Descemet's membrane and anterior iris surface. PAS. $\times 800$
Table 2 Distribution of cases of endothelialisation of the anterior chamber

\begin{tabular}{ll}
\hline Category & Number of cases \\
\hline 1. Trauma A. Surgical & 2 \\
B. Non-surgical & 9 \\
2. Central retinal artery occlusion & 2 \\
3. Diabetes mellitus & 1 \\
4. Peters's anomaly & 1 \\
5. Unknown & $\frac{2}{17}$ \\
\hline
\end{tabular}

thin and partial and extended only a short distance from the pseudoangle.

\section{Discussion}

Corneal endothelium and Descemet's membrane may under certain circumstances extend from their normal position on the cornea: (1) over the trabecular meshwork following anterior chamber angle recession (Wolff and Zimmerman, 1962); (2) over the iris in association with the iris naevus syndrome (Klien, 1941; Cogan and Reese, 1969; Wolter and Makley, 1972; Scheie and Yanoff, 1974); (3) over the anterior iris surface in association with peripheral anterior synechiae (Wagenmann, 1889); and (4) in essential iris atrophy (Heath, 1953).

Collins (1927) reported a case of buphthalmos 
where failure in the normal development of the anterior chamber angle was associated with a continuation of Descemet's membrane at the angle on to the surface of the iris. Reese (1944) noted the presence of Descemet's membrane on the trabecular area in association with open-angle glaucoma. Lauring (1969) reported 19 cases of Descemet's membrane extending on to the iris. In 13, peripheral anterior synechiae were present while in 6 , which occurred after trauma, Descemet's membrane and endothelium extended over the recessed angle. Wolff and Zimmerman (1962) in their study of traumatic recession of the angle described Descemet's membrane extending over the inner surface of the trabecular meshwork and the recessed angle or extending from the pseudoangle formed at the attachment of peripheral anterior synechiae. Klien (1941) reported a patient, and Cogan and Reese (1969) added 2 additional cases in which superficial iris nodules were associated with peripheral anterior synechiae and extension of corneal endothelium and Descemet's membrane on to the iris surface. The nodules on histopathological examination were naevi and they called the condition the iris-naevus syndrome. Wolter and Makley (1972) reported a similar case. Scheie and Yanoff (1975) reported 14 such patients, all of whom had glaucoma, peripheral anterior synechiae, and iris nodules. Many had ectropion uveae. In 3 of their cases histopathological examination revealed extension of the corneal endothelium and Descemet's membrane on to the anterior iris surface. Additionally, late failure of filtering surgery for glaucoma in association with the iris naevus syndrome may be due to endothelialisation of the filtering bleb associated with the production of a thick basement membrane (Yanoff et al., 1976).

Waring et al. (1974) in a review of the laterature of pathological alteration of Descemet's membrane found no adequate explanation for the normal limitation of the endothelium and Descemet's membrane to the cornea nor for its extension on to the iris. Review of the literature reveals 2 modes of extension of Descemet's membrane. In 1 type Descemet's membrane grows over the trabecular meshwork of an open or recessed angle. Most of these cases followed trauma associated with angle recession. The other type is an extension of Descemet's membrane from the cornea at the pseudoangle formed by peripheral anterior synechiae on to the iris surface. Most of the cases in the literature as well as our 17 cases are of the second type. Since all of our cases reported here were in association with rubeosis iridis this number suggests that rubeosis iridis may be a factor in the extension of endothelium and Descemet's membrane on to the iris.

The accepted explanation for the development of ectropion uveae is that contraction of the fibrovascular membrane of rubeosis iridis pulls the iris pigment epithelium from the pupillary border on to the anterior iris surface. Although a definitive explanation for the extension of endothelium and Descemet's membrane on to the iris has not been set forth, it seems likely that the presence of the neovascular membrane attached to the cornea at the pseudoangle can in some way stimulate the extension of the endothelium on to the anterior iris surface. Though there are many conditions that are associated with the development of rubeosis iridis, the end result of corneal endothelium and Descemet's membrane extending on to the iris is very similar regardless of the cause of the rubeosis iridis. We found essentially identical findings in cases which followed or were in association with trauma, surgery, diabetes mellitus, Peters's anomaly, and closure of the central retinal artery.

\section{References}

Cogan, D. G., and Reese, A. B. (1969). Documenta Opthalmologica, 26, 424.

Collins, T. (1927). Transactions of the Ophthalmological Society of the United Kingdom, 47, 155.

Heath, P. (1953). Transactions of the American Ophthalmological Society, 51, 167.

Klien, B. A. (1941). American Journal of Ophthalmology, 24, 133.

Lauring, L. (1969). American Journal of Ophthalmology, 68, 308.

Reese, A. B. (1944). American Journal of Ophthalmology, 27, 1193.

Scheie, H. G., and Yanoff, M. (1975). Archives of Ophthalmology, 93, 963.

Wagenmann, A. (1889). Albrecht v. Graefes Archiv für Ophthalmologie, Vereinigt mit Archiv für Augenheilkunde, 35, 1.

Waring, G. O., Laibson, P. R., and Rodrigues, M. (1974). Survey of Ophthalmology, 18, 325.

Wolff, S. M., and Zimmerman, L. E. (1962). American Journal of Ophthalmology, 54, 547.

Wolter, J. R., and Makley, T. A. (1972). Journal of Pediatric Ophthalmology, 9, 102.

Yanoff, M., Scheie, H. G., and Allman, M. J. (1976). Archives of Ophthalmology, 94, 1933. 